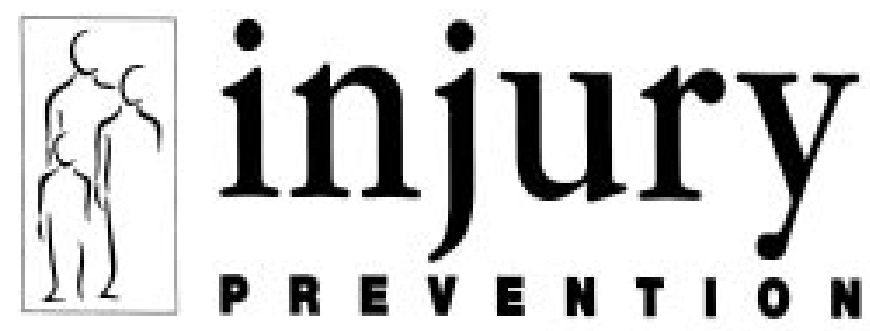

Journal of the International Society for Child and Adolescent Injury Prevention

\title{
Guest editorials
}

\section{Reintegrating injury prevention}

This could be a landmark year for the journal. The future inclusion of research on injuries to persons of all ages is a welcome move toward reintegration of all aspects of the field under one banner. The interdisciplinary cooperation necessary to advance injury prevention has too often been negated by turf wars. There is an unfortunate side effect of cooperation, however. Too much credence or resources may be devoted to approaches that are ineffective or counter productive.

The classic article by Haddon reprinted in this issue reminds us that injury prevention is an integral part of a public health tradition that has often been ignored or misunderstood by those who think that injury is caused largely by misbehavior. Injury and illness are physical and biological processes that have numerous points for potential intervention. Since most people are behaving in some way or another when they are injured, behavior is obviously a factor as well. One of the more persistent fights of Haddonites is with behaviorists who resist the Haddon approach to injury prevention.

If there is something in the water from the Broad Street Pump that is killing people, do we launch a campaign to persuade each individual to get their water elsewhere, or do we shut down the pump? The guard rail that prevents you from going over a cliff does not care whether you left the road because of inattention, drunkenness, distraction by others in the vehicle, adolescent hubris, or a wasp in the car. It just does its job. When high schoolers decide to play video games among their classmates with live ammunition, the death and injury toll is less a function of parental neglect, violent video games, or the hormones of the shooters than it is the nature of the weapons (caliber, bullet shape, number of rounds in a clip, capability of automatic or semiautomatic fire). Concentration on unchangeable host characteristics, such as age, gender, or behaviors that are difficult to change on an individual basis, is a prescription for unnecessary suffering.

Most of the successful attempts at behavioral change are targeted at public behaviors that can be sanctioned by law enforcement, such as requiring seat belt use.

Fragmentation is inevitable as researchers and practitioners develop specialties. This is particularly true in a field that involves several disciplines. The revitalization of interest in injury in the US was accelerated in government by Injury in America, a book prepared by a National Research Council/Institute of Medicine committee. ${ }^{1}$ As a member of that committee, I was amazed and gratified at the lack of turf defense among the disciplines represented-behavioral science, biomechanics, epidemiology, statistics, surgery, rehabilitation. Each member of the committee showed extraordinary respect for the contribution of disciplines other than their own and the need for monetary support of research in all the disciplines.

Sadly, within three years after the report was released, as a modest amount of new money became available from the Centers for Disease Control (CDC), battles for the "pittance", as Julian Waller aptly characterized it, formed largely along disciplinary lines. For example, a surgeon complained to me that the new Director of the CDC effort was an epidemiologist who was giving epidemiologists advanced information to help them with grant proposals. In fact, the allegation was easily shown to be unfounded as the Director had specialized in sexually transmitted diseases and was unknown to injury epidemiologists. Because of his lack of expertise in the field, many injury epidemiologists did not welcome his appointment. Psychologists complained that there were no psychologists on the National Research Council/Institute of Medicine committees, apparently unaware that my training was primarily in social psychology, albeit in a sociology department, or that Park Dietz had psychiatric training. The point of the consensus in the Injury in America committee is that disciplinary loyalty, ideology, or whatever you wish to call it, must be set aside when assessing needs regarding prevention.

In subsequent efforts at consensus documents, attempts were made to appease those who claimed that their disciplines or emphases were being left out. Of six "challenges facing injury prevention programs" discussed in Injury Prevention: Meeting the Challenge, one said, "Our society glorifies risk taking; safety has a poor public image". ${ }^{2}$ Changing attitudes by long term education was proposed as the solution. There is no entity with a brain called "society". There are communications and entertainment media that portray risky behavior and conflict resolution with guns as common occurrences, appealing to the needs of some adolescents of whatever age for high levels of stimuli. Yet these are hardly representative of the behaviors or "attitudes" of the majority of the population. If John Snow were to find deaths associated with a water supply today, I fear that we might be urged to undertake a long term education campaign to change peoples attitudes toward that water supply, rather than remove the handle from the pump. 
Part of my training was in attitude measurement. It didn't take me long to learn that attitudes do not translate into actions. One of the most powerful effects on behavior is a desire for approval of others. Much inaction relative to attitudes and beliefs is the result of pluralistic ignorancethe often mistaken belief that the attitudes and beliefs of people whose approval is sought is different from one's own attitudes and beliefs. My first injury study compared people's attitudes toward seat belts and their use of them. The majority had positive attitudes but was observed sitting on the belts.

The most recent attempt at a consensus assessment in the field was produced by a committee formed by the Institute of Medicine in the US, entitled Reducing the Burden of Injury: Advancing Prevention and Treatment. ${ }^{3}$ The document has several inaccuracies and unreferenced assertions. For example, US governmental authority to set safety standards for motor vehicles is attributed to the Highway Safety Act of 1966 which actually gives federal authority to assist states in highway safety programs. Safety standards were authorized by the Motor Vehicle Safety Act. The first airbags are attributed to General Motors in 1974. They were actually produced by Eaton, Yale, and Towne in the late 1960s.

The notion that reduction of risk by safety standards and other environmental modifications is offset by changes in risky behavior is given credence without supporting refer- ences and despite a plethora of contrary evidence in the peer reviewed literature. Did the inaccuracies and mediocrity in that report, despite many highly competent committee members, occur because of pluralistic ignorance, compromise, or perhaps out of deference to an overworked staff?

Too much death and disability occurs because what we know is not applied. We must be willing to confront governments and corporations whose policies and products fail to incorporate the science that we have developed. And those of us on consensus committees, funding review boards, or editorial boards, must confront colleagues and friends working in injury prevention who are ignorant of prior research on what works and what does not. We also need to confront those who put disciplinary loyalty above concern for the injured. It's a dirty job, but somebody has to do it.

160 Sharps Road,

LEON ROBERTSON

Globe, AZ 85501, USA

1 Committee on Trauma Research, Commission on Life Sciences, National Research Council and Institute of Medicine. Injury in America: a continiung public health problem. Washington, DC: National Academic Press, 1985.

2 National Committee for Injury Prevention and Control. Injury prevention: meeting the challenge. New York: Oxford University Press, 1989 (supplement meeting the challenge. New York: Oxford Univers
to the American fournal of Preventive Medicine).

3 Committee on Injury Prevention and Control, Institute of Medicine. Reducing the burden of injury. Washington, DC: National Academy Press, 1999.

\section{Injury prevention is growing up!}

Injury Prevention has rapidly established itself as the lead journal in its field. Although there are sister publications that address issues of injury causation and consequences, no other journal has embodied the full scientific spectrum from epidemiology, causation, and outcomes, to countermeasure development, implementation, and evaluation. In fact this successful concentration on child and adolescent injury has thrown into sharp relief the need for the same comprehensive approach to research dissemination across all ages.

A focus on child injury has provided the catalyst for better organised and systematic community approaches to injury prevention in a number of countries. Such has been the case in the United Kingdom and Australia after establishment of trusts or foundations that have had a profound impact on community and government responses to the importance of injury prevention. Injury surveillance has been an important contributor to this.

In Australia, injury surveillance was developed, piloted, and implemented for children's injuries in the first instance before being expanded to cover injuries in persons of all ages. $^{12}$

Successful integrated models of injury prevention incorporate rigorous scientific principles, including those that recognise the importance of social determinants and modifiers of risk and countermeasure success. Such models seek to identify the uniqueness of the human, environmental, biomechanical, social and indeed political factors that mediate particular injuries. This includes age, of course, and the counterparts of those special conditions applying to the young are just as important to recognise in the elderly and indeed at all stages of life.

Injury prevention research has been relatively poorly funded throughout the world, and especially in the emerging market economies of the third world. Recent developments have, however, begun to influence research expenditure around the world. Government, corporate, and philanthropic backers of research want more of a say in how their research investment is spent, particularly focusing on demonstrable gains in health as a result of that investment.

In the United States and Australia, for example, major reviews of research expenditure have led to substantial increased government commitment to funding health and medical research of all kinds, but especially research that addresses health priorities, particularly those that reflect high levels of health spending. ${ }^{34}$

In Australia, this focus has also led to the establishment of a national advisory council on injury prevention, production of a major analysis of research needs in the injury prevention area, ${ }^{5}$ and new national strategies for both research and action on injury prevention. ${ }^{6}{ }^{7}$ Some of this discovery of the importance of prevention and orientation to so-called strategic research has been influenced by the World Bank and World Health Organisation ad hoc committee report on health research ${ }^{8}$ and the associated Global Burden of Disease project. ${ }^{9}$ In the latter exercise, Murray and Lopez demonstrated that injury is a major contributor to global death and disability, ${ }^{9}$ particularly injuries attributable to road trauma and to falls. They project that by 2020, road traffic injury (ranked ninth in 1990) will rank third in the league table of global disability burden behind only ischaemic heart disease and major depression. War and violence may, on their estimates, increase their world ranking from 16 to 8 and from 19 to 12 respectively.

The challenge for the research community is to harness this new support, and to pick up the pace on injury prevention research, especially in relation to the developing world. In its new form Injury Prevention will be well placed to promote this growth and particularly to encourage publication of injury research likely to benefit all, particularly those in the emerging market economies.

TERRY NOLAN 
Professor, Department of Paediatrics (University of Melbourne), Clinical Epidemiology and Biostatistics Unit,

Level 4, Front entry building,

Royal Children's Hospital,

Flemington Road, Parkville 3052, Australia

(Phone: +61-3-9345-6363, fax: +61-3-9345-6000,

e-mail:nolan@cryptic.rch.unimelb.edu.au)

1 Nolan TM, Penny M. Epidemiology of accidents in an Australian urban region-results from injury surveillance. $\mathcal{F}$ Paediatr Child Health 1992;28:27-35.

2 Ozanne-Smith J, Routley V, eds. Injury data and prevention. Hazard Vol 3 , editions 21-30. Melbourne: Monash University Accident Research Centre, December 1997.

3 National Institutes of Health (NIH). The president's fiscal year 1999 budget for NIH. http://www.nih.gov/news/Budget99/BUDGET99.HTM
4 The virtuous cycle: working together for health and medical research. Health and medical research strategic review. Canberra: Commonwealth of Australia, 1999.

5 Strategic Research Development Committee of the National Health and Medical Research Council. Paradigm shift. Injury, from problem to solution: new research directions. Canberra: Department of Health and Aged Care, Commonwealth of Australia, March 1999.

6 National Injury Prevention Advisory Council. Directions in Injury Prevention. Report 1: research needs. Commonwealth of Australia, 1999.

7 National Injury Prevention Advisory Council. Directions in Injury Prevention. Report 2: injury prevention intervention-good buys for the next decade. Commonwealth of Australia, 1999.

8 Investing in Health Research and Development. Report of the ad hoc committee on health research relating to future intervention options. Geneva: World Health Organisation, 1996 (document TRD/Gen/96.1)

9 Murray CJL, Lopez AD, eds. The global burden of disease. The Global Burden of Disease and Injury Series, Vol 1. Harvard: Harvard University Press, 1996.

\section{Editorial}

\section{An editor's dilemma-avoiding conflict of interest}

To paraphrase Gilbert and Sullivan, “An editor's lot is not an easy one". In truth, it is usually stimulating but at times, it can be challenging. One such occasion arises when faced with situations that may appear to present a conflict of interest. In this issue, I am the second author of two papers.

Clearly, this is open to question. To help allay concerns and set my conscience at rest, I want to explain to readers how we handle any circumstance like this. The problem arises, of course, because the senior (corresponding) author usually has the final word about the journal to which a paper is sent. Naturally, any sensible author with a good paper in the injury prevention field would first consider sending it to this journal. It would be wrong to deny them the opportunity to do so.

It would be foolish to pretend coauthors are not influenced by my role as editor, although (as I will explain) I make a point of warning my colleagues that I will not be involved in any way. I also alert them to the fact that with me (or others like me as a coauthor) the review process may actually be tougher. It would not be too surprising to discover that reviewers set higher standards for papers in which a well established investigator is a coauthor, and perhaps higher still for those in which editors are foolish enough to expose themselves to scrutiny.

Thus, in any instance where I am involved in any capacity in a paper submitted to the journal, I assign the entire review process to one of the associate editors chosen independently by the assistant editor. The associate then chooses reviewers, responds to their comments, makes the final decision, and informs the corresponding author of the decision. If there is a request for revisions, the associate editor alone decides if a resubmission has met the criticisms adequately. In short, I play no part whatsoever until after all judgment calls are made.

With respect to the two papers in this issue, however, I faced another dilemma. I had to decide whether to include them in the same issue. Normally, I try to avoid having more than one paper from the same group in one issue. In this instance, however, the topics were so intimately related that there seemed to be a compelling reason for publishing them side by side. The difficulty was somewhat mitigated by the fact that they come from different institutions.

Therefore, my conscience is clear. But to further protect it, I invited Drs Stone, Morrison, and Smith to write a commentary on the topic addressed by the papers in question-surveillance (see p166). In spite of my having helped create the Canadian system described in the papers by Mackenzie and Macarthur, CHIRPP, I now have mixed feelings about the benefits of surveillance systems. After hearing Stone and Smith express some of those reservations at a recent meeting, especially with respect to surveillance based exclusively in emergency departments, it seemed essential to include their comments.

When I began my efforts to have the CHIRPP surveillance system established in Canada I did so because I thought we needed more data to raise the profile of the injury problem. It is hard to tell how well CHIRPP served this purpose. It provided new and better information about causal factors, which, in turn, should lead to better preventive measures. So I think a system like CHIRPP, that includes open text fields for a description of "what happened", is appealing.

Nevertheless, the points raised by Stone et al about whether we need to include every hospital attendance to achieve our goals deserves consideration. Similarly the concerns about the bias of hospital data are probably justified but may be correctable. In short, surveillance systems can and probably should be improved and those that don't have them probably should. But there are other caveats.

Quite apart from the important methodological issues raised in the commentary, we also need to assess whether surveillance systems serve their ultimate goals. Most assume that the more data we can collect and the better their quality, the more quickly we will achieve the goal of preventing injuries. However, if these data are not often used, or not used well, this assumption does not hold. Certainly, if the sponsors of the surveillance systems use all or most of their resources to collect these data and have little or none left to support prevention programsgovernmental, non-governmental organisations, or voluntary, community groups - one cannot help but question the wisdom of the exercise. It is time to rethink the whole question of surveillance and force its advocates to answer these tough questions along with those posed by the authors of the commentary.

I B PLESS Editor 


\section{Joining with the adults}

It has been more than three months since the decision was made to expand the journal to injuries of all ages. As a pediatrician who spends at least half of his research time focused on injuries in adults, I fully support this decision by the editor, the editorial board, and the BMJ Publishing Group. Change, while never easy, can be a learning experience. What can those of us who work in the child and adolescent injury prevention field learn from our "adult" colleagues and what do they have to learn from us?

Much of the research and intervention programs discussed in these pages have focused on injuries to children and little, especially relative to its importance, has focused on adolescents. The addition of a readership and authors interested in injuries to adults should enhance the amount of information relevant to adolescents. Many risk factors for injuries in young adults also operate in later adolescence, and many prevention programs will be equally applicable to youth from adolescence to adulthood. For example, most studies that have examined the role of substance abuse in injuries have focused on injuries in adults. Nearly all the studies and trials of brief interventions for substance abuse have also focused on this age group, and have found that such programs can reduce drinking and decrease the risk of injury recidivism. ${ }^{12}$ Injury control programs for adolescents have much to learn from these "adult" interventions.

Other types of injury problems, while much more common in adults, are nevertheless frequent and serious in children and adolescents. Firearm related injuries are one example; in the US, most deaths due to firearms occur in adults. $^{3}$ Yet, interventions for these injury problems can potentially affect people of all ages, even if they are focused on a certain age group. Reducing access to guns for teens can potentially reduce the risk of homicide to teens and adults. Personalizing guns so they can be used just by one individual may reduce the risk of gun death to people of all ages. Tracking firearm injuries will benefit all in the community.

Some injury prevention interventions will simply not be possible unless we team with our adult colleagues. Safer vehicles with better occupant protection, fire safe cigarettes, safer roads for pedestrians, and more widespread use of smoke detectors, will be much slower in coming if individuals concerned with injuries in adults as well as children are not deeply involved.

The relevance of "adult" programs to children is not limited to those programs targeting young adults. The elderly represent a group that is viewed at least as vulnerable and worthy of protection as are young children. For example, traffic calming interventions to reduce the speed and density of traffic have equal applicability to the very young as to the very old. The addition of the older age groups may make advocacy for such programs more feasible and successful. While children don't vote, the elderly certainly do!

Community intervention programs may do well to expand their coverage to include adults, and by doing so, enhance their effectiveness for children and adolescents. We all know the importance of adults as role models; this applies to safety behavior as well. For example, in our bicycle helmet campaign we found that among children riding with helmeted adults, more than $95 \%$ of the children are helmeted, whereas if the adult is unhelmeted, more than two thirds of the accompanying children will also be unhelmeted. ${ }^{4}$ Targeting adults may be the easiest way to reach the children.

We can also teach our "adult" colleagues a great deal. The leading advocates for injury prevention around the world have come from the ranks of individuals seeking to prevent injuries to children, such as people like Hugh Jackson, Ragnar Berfenstam, Bernard Leveque, and Abraham Bergman. These child advocates can serve as role models for the prevention of injuries to other vulnerable groups such as the elderly, the poor, and the foreign born. Far more success stories come from pediatric injury prevention strategies than from those focused exclusively on adults. Poison packaging, flammable fabric safety, pool safety, and tap water burn prevention are all marvelous examples of injury prevention strategies in the pediatric field.

Most children in the world are cared for by physicians who primarily practice adult medicine, whether they be general practitioners or surgeons. These individuals need to be educated about the risk factors for injuries to children and adolescents, as well as about the interventions which work (and those which don't). What better way to do this than by sharing our work in the same journal?

Some of the injury problems which we see today might not have occurred if there was more interchange between those concerned with pediatric and those concerned with adult injury prevention. For example, one of the largest nightmares for car manufacturers and the National Highway Safety Administration in the US over the last few years has been children injured or killed by airbags. ${ }^{5}$ One of the reasons this occurred is that the regulations were written to protect a standard $70 \mathrm{~kg}$ male; not enough consideration was given to the potential effects on a much smaller child occupying the front seat. The result has been redesign of airbag systems to take into consideration the size of the front seat occupant, development and testing with a whole new "family" of child size dummies, and a large public education campaign to get the kids in the back.

Individuals studying child injuries have generally paid much more attention to psychosocial factors which increase the risk of injury as well as those affected by the occurrence of trauma. For example, information on the effects of poverty on injury risk have primarily come from pediatric studies. ${ }^{67}$

The injury field has much to gain from this decision and I am sure will, through the pages of the journal. At the inaugural meeting for Injury Prevention, Barry Pless called us to be interdisciplinary, not just multidisciplinary. This expansion of our focus is a large step in that direction. At the same time, it further enhances the importance of the International Society for Child and Adolescent Injury Prevention to serve as an advocate for children and to make sure their voice continues to be heard.

FREDERICK P RIVARA

Harborview Injury Prevention and Research Center, Chair, ISCAIP

Box 359960, 325 Ninth Ave,

Seattle, WA 91804, USA

(Tel: + 1206521 1530,fax: +1 206521 1562,

e-mail:fpr@u.washington.edu) 
1 Gentilello LM, Rivara FP, Donovan DM, et al. Alcohol interventions in a trauma center as a means of reducing the risk of injury recurrence. Ann Surg trauma center

2 Bien TH, Miller WR, Tonigan JS. Brief interventions for alcohol problems. A review. Addiction 1993;88:315-35.

3 Blumstein A, Rosenfeld R. Exploring recent trends in US homicide rates. fournal of Criminal Law and Criminology 1998;88:1175-216.

4 Bergman AB, Rivara FP, Richards DD, et al. The Seattle Children's Bicycle Helmet Campaign. Am $\mathcal{F}$ Dis Child 1990;144:727-31.
5 Graham JD, Goldie SJ, Segui-Gomez M, et al. Reducing risks to children in vehicles with passenger airbags. Pediatrics $1998 ; 102$ : 3 .

6 Anderson CL, Agran PF, Winn DG, et al. Demographic risk factors for injury among Hispanic and non-Hispanic white children: an ecologic analysis. Inj Prev 1998;4:33-8.

7 Overpeck MD, Jones $\mathrm{DH}$, Trumble $\mathrm{AC}$, et al. Socioeconomic and racial/ethnic factors affecting non-fatal medically attended injury rates in US children. Inj Prev 1997;3:272-6.

Cars parked in direct sunlight can reach internal temperatures of up to $78^{\circ} \mathrm{C}\left(172^{\circ} \mathrm{F}\right)$ when outside temperatures are between $27^{\circ} \mathrm{C}$ and $38^{\circ} \mathrm{C}\left(80^{\circ}-100^{\circ} \mathrm{F}\right)$. The temperature increase usually happens in the first 15 minutes in the sun. The Centers for Disease Control reports that during one month in 1998, no fewer than 11 children died in three separate incidents after being trapped in the boots (trunks) of cars. All were aged 6 years or younger. Denying children access to car keys, keeping cars locked and boots closed, and supervising young children around cars are possible preventive measures ( $\mathcal{A} A M A 1999 ; 281: 505-6)$.

When a 5 month old give was ejected from a motor vehicle in a crash, she was apparently uninjured but for a mark on the forehead. Astute clinicians examined the computed tomogram in detail and found a cervical spine fracture which may have been missed had the clue of the forehead abrasion not been followed up (Pediatric Emergency Care 1998;14:299-301).

Two Canadian boys sustained groin and perineal injuries while sledding on snow racers. Snow racers consist of a sled mounted on two skis steered by a third ski in the front without a protective front panel and may need to be redesigned to avoid similar injuries (Canadian Medical Association fournal 1999;160:353-4).

A 2 year old girl became unwell some hours after a trip to the country, appeared to recover, but died three days later. It was only in retrospect that it became known that during the rural visit she had eaten leaves of unknown origin. Oleandrin was found at autopsy, confirming that the leaves were oleander leaves (Ambulatory Child Health 1998;4:415-19).

Maybe chest rubs containing camphor, turpentine oil, menthol, and eucalyptus oil should be packaged in child resistant containers. One 20 month old girl who ingested chest rub suffered a generalised seizure. The parent was unaware the product was toxic and had left the product in an accessible place (Fournal of Paediatrics and Child Health 1999;35:105-6).

Using babies' bottles to measure and store methadone is novel, but apparently common in Dublin, particularly in households with children. Doctors prescribing methadone are encouraged to supply alternative measuring devices to avoid children becoming exposed to methadone mistakenly (BMF 1999;318:329-30).

Ceiling fans are popular in tropical climates with over $90 \%$ of households in Townsville, Queensland, owning them. Injuries ranging from skull fractures to grazes attributed to ceiling fans were sustained by 50 people, including 22 children under 15 years, in two years. Seven children were injured while on the top of bunk beds. Fans should be guarded, and information provided at point of sale and should include recommendations about the height of fan placement (Medical fournal of Australia 1999;170:119-20).

Home roasted chestnuts should be pierced before cooking to allow moisture to escape and avoid the shells causing eye injuries if they explode (Burns 1999;25:277).

Some glass fronted gas fireplaces can heat to over $245^{\circ} \mathrm{C}$ and have the potential to inflict severe contact burns. Guards around the fireplaces, warning labels on the units and ignition switches, and prevention information in the manual are recommended preventive measures (Fournal of Burn Care and Rehabilitation 1999;20:86-9). 